\title{
Sosialisasi Penerapan Smart e-Monitoring Untuk Pasien Covid-19 Berbasis IoT di STIPARK NTB
}

\author{
Indra Gunawan*1, Nurhidayati ${ }^{2}$, Lalu Kerta Wijaya ${ }^{3}$, Farid Wajdi ${ }^{4}$ \\ Artha_3119@yahoo.com*1 \\ ${ }^{1,3,4}$ Program Studi Teknik Informatika, Fakultas Teknik, Universitas Hamzanwadi \\ ${ }^{2}$ Program Studi Sistem Informasi, Fakultas Teknik, Universitas Hamzanwadi
}

Received: 30 October 2021 Accepted: 07 December 2021 Online Publisher: 30 December 2021

DOI: 10.29408/ab.v2i2.4203

\begin{abstract}
Abstrak: Program Kompetisi Kampus Merdeka (PKKM) yang diadakan oleh Kementerian Pendidikan, Kebudayaan, Riset, dan Teknologi merupakan program pembiayaan yang memiliki tujuan untuk memfasilitasi, mendorong, dan mempercepat transformasi perguruan. Prodi Teknik Informatika, Universitas Hamzanwadi sebagai salah satu perguruan tinggi yang menerima hibah tersebut mengembangkan aplikasi berbasis Internet of Things untuk memantau perkembangan pasien Covid-19 yang melakukan isolasi mandiri yang bernama SMART e-MONITORING. Oleh sebab itu, kegiatan ini bertujuan untuk mensosialisasikan penerapan aplikasi ini di STIPARK NTB. Kegiatan ini dilakukan secara bertahap, selama 4 bulan. Dimulai dari presentasi produk, sampai dengan proses uji coba sistem dan launching produk. Hasil kegiatan menunjukkan bahwa aplikasi yang dikembangkan dapat berjalan dengan baik, dan dapat menampilkan kondisi pasien secara realtime. Data yang direkam antara lain data suhu tubuh, kadar oksigen (SPO2), dan data denyut jantung (BPM). Data ini digunakan untuk memudahkan dalam penanganan pasien isolasi mandiri secara realtime dan tanpa bersentuhan langsung dengan pasien Covid-19.
\end{abstract}

Kata kunci: Covid-19; Internet of Things; Smart e-Monitoring

Abstract: The Merdeka Campus Competition Program, held by the Ministry of Education, Culture, Research, and Technology, is a financing program that aims to facilitate, encourage, and accelerate the transformation of higher education institutions. Informatics Engineering Study Program, Hamzanwadi University, as one of the universities that received the grant, developed an Internet of Things-based application to monitor the progress of Covid-19 patients who are self-isolating called SMART e-MONITORING. Therefore, this activity aims to socialize the Smart e-Monitoring application at STIPARK NTB as partners. This activity was held over four months. It's were starting from product presentations to system testing and product launching. The activity results show that the developed application can run well and display the patient's condition in real-time. The recorded data include body temperature data, oxygen levels (SPO2), and heart rate (BPM). This data is used to facilitate the handling of selfisolated patients in real-time and without direct contact with Covid-19 patients.

Keywords: Covid-19; Internet of Things; Smart e-Monitoring 


\section{PENDAHULUAN}

Universitas Hamzanwadi adalah salah satu Universitas yang terpilih dalam kegiatan Program Kampus Merdeka (PKKM) dari sekian banyak Universitas dan sekolah tinggi di Indonesia, kegiatan PKKM ini salah satunya di ikuti oleh program studi Teknik Informatika (Suhartini, dkk., 2021). Program Studi Teknik Informatika Universitas Hamzanwadi sebagai salah satu institusi pendidikan tinggi diharapkan dapat menghasilkan lulusan yang dapat diserap dunia kerja (Putra dkk., 2020). Dalam memenuhi tuntutan tersebut ada dua isu yang dihadapi yaitu kualitas pembelajaran dan relevansi antara kompetensi dengan kebutuhan pasar. Artinya, kualitas pembelajaran sangat ditentukan oleh relevansi dengan kompetensi yang dituntut oleh dunia kerja. Dengan demikian pengembangan Program studi memerlukan informasi yang akurat dari lapangan, sehingga pengembangan tersebut sesuai dengan kemajuan dan tuntutan zaman (Arianti, dkk., 2020). Salah satu tahapan kegiatan yang dilakukan dalam rangka meningkatkan kemampuan dan pengetahuan kompetensi mahasiswa adalah melaksanakan kegiatan Magang Industri yaitu berlokasi di Science Techno \& Industrial Park (STIPARK) NTB.

Fungsi lembaga STIPARK NTB salah satunya adalah lembaga inkubasi untuk pelaku mitra baik mitra usaha maupun mitra pemerintah dalam pengembangan teknologi, sebagai mitra pemerintah selaku lembaga di bawah pemerintah sedang berupaya membantu dinasdinas terkait seperti dinas kesehatan, pendidikan dan lainnya, kolaborasi antara mitra-mitra baik dinas kesehatan dan mitra usaha teknologi seperti dalam pengembangan sepeda listrik saat ini dan berupaya dalam pengembangan teknologi lainnya seperti membuat suatu produk inovasi dalam rangka membantu pemerintah terutama dalam hal penanganan pasien Covid-19, yang menjadi permasalahan selama ini adalah indikator beberapa pasien Covid-19 (Saputra, 2020) yang sedang menjalani isolasi mandiri bahkan sudah sembuh dan dinyatakan boleh isolasi mandiri ada beberapa kasus meninggal diakibatkan oleh baik dari kadar oksigen pasien yang tiba-tiba drop, untuk mengatasi dan membantu pemerintah dalam mengatasi dan mencoba berinovasi agar bisa dimanfaatkan untuk pasien homecare salah satu diantaranya adalah teknologi untuk memonitor data kesehatan pasien secara mandiri dan dipantau secara jarak jauh misalnya di pusat data rumah sakit (Septiana dkk., 2020). Dengan adanya permasalahan dan keinginan mitra tersebut mahasiswa program studi teknik informatika yang sedang melakukan proses magang beserta dosen berinisiatif membuat pengembangan produk hasil penelitian yang sudah dilakukan dengan membuat produk inovasi untuk membantu permasalahan tersebut sebagai bentuk pengabdian kepada masyarakat. Alat yang akan dibuat yaitu sebuah sistem monitoring secara realtime kesehatan yaitu bernama SELMO (SelfMonitoring) (Pratiwi, 2021).

Kegiatan magang industri yang dilakukan oleh mahasiswa Program Studi Teknik Informatika Fakultas Teknik Universitas Hamzanwadi, dalam rangka Program Kompetisi Kampus Merdeka memberikan kontribusi dalam bentuk pengabdian dengan memberikan sosialisasi dan penerapan produk hasil penelitian yang sudah dilakukan untuk diimplementasikan di STIPARK NTB sebagai mitra dalam proses kegiatan magang industri. 


\section{METODE PELAKSANAAN}

\section{Waktu dan tempat}

Waktu kegiatan pengabdian ini adalah dilaksanakan pada bulan Juni sampai bulan November 2021 dan tempat pelaksanaan Penerapan produk alat inovasi hasil penelitian berada di lokasi Science Techo Industrial Park (STIPARK) NTB.

\section{Prosedur pelaksanaan}

Kegiatan pengabdian kepada masyarakat (PKM) ini dimulai dengan terlebih dahulu dimulai dengan beberapa tahapan yaitu melakukan analisa permasalahan yang sedang trend dan kemudian perencanaan kegiatan yang akan dilakukan, pengembangan sistem, uji coba sistem dan sosialisasi ke mitra yaitu STIPARK dan pengujian kepada warga yang akan mengikuti kegiatan ini, Kegiatan ini selain dilaksanakan oleh tim dosen juga dibantu oleh beberapa mahasiswa program studi Teknik Informatika sebagai bentuk proses magang industri keterlibatan mahasiswa yaitu membantu proses saat berada pada tahap perencanaan, menganalisis permasalahan yang dibutuhkan untuk dapat melaksanakan kegiatan pengabdian kepada masyarakat ini (Sutisna, dkk., 2020). Kegiatan pengabdian masyarakat ini dilaksanakan selama 4 bulan yang dilakukan secara bertahap sampai proses uji coba sistem dan serah terima produk inovasi kepada pengurus STIPARK dan Instansi baik Rumah sakit maupun masyarakat yang nanti membutuhkan.

Adapun secara umum kegiatan ini dilakukan dengan 2 cara tahap yaitu:

1. Sosialisasi presentasi ke tim STIPARK

Dalam kegiatan sosialisasi ini peserta magang yaitu mahasiswa presentasi untuk sosialisasi kira-kira produk inovasi apa yang bisa akan dikembangkan di STIPARK sebagai bentuk pengabdian dan kerja sama dengan lembaga masyarakat, berdasar dari analisa permasalahan dan kebutuhan yang dialami maupun yang sedang trend saat ini dalam masyarakat.

2. Pengembangan dan Penerapan Produk Inovasi

Proses kegiatan berikutnya yaitu setelah ditemukan permasalahan dan disepakati produk hasil penelitian yang bisa dikembangkan di STIPARK tim peserta magang kemudian melakukan persiapan dan analisa kebutuhan dan bagaimana penerapan alat dalam uji coba ke mitra masyarakat.

Kerangka pelaksanaan kegiatan pengabdian kepada masyarakat dalam penerapan produk alat inovasi hasil penelitian ini dapat dilihat pada gambar 1.

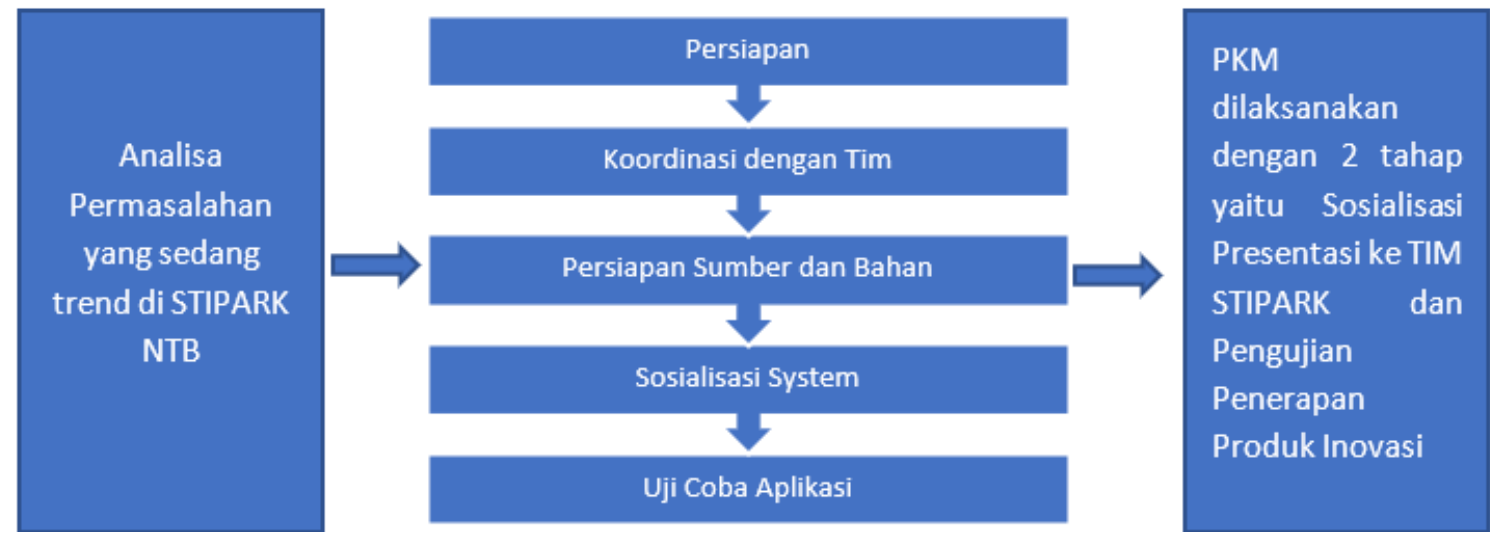

Gambar 1. Kerangka Kerja Pelaksanaan Pengabdian Kepada Masyarakat 


\section{HASIL DAN PEMBAHASAN \\ HASIL}

Kegiatan magang industri mahasiswa ini dilaksanakan selama 4 bulan (14 Juli - 14 November 2021) yang dilakukan secara bertahap diawali dari sharing dan konsultasi ke TIM STIPARK. Dalam kegiatan pengabdian ini dihasilkan sebuah produk hasil penelitian yang merupakan kerja sama antara Fakultas Teknik Universitas Hamzanwadi dengan STIPARK NTB yaitu produk Smart E-Monitoring bernama SELMO (self monitoring), SELMO ini merupakan sebuah alat untuk membantu petugas medis agar pasien isolasi mandiri ataupun pasien karantina dapat dipantau secara realtime dan tanpa kontak langsung dengan pasien yaitu data dikirim dari jarak jauh secara nirkabel ataupun internet, data yang dikirimkan yaitu berupa data kondisi pasien baik suhu tubuh, kadar oksigen (SP02) dan denyut jantung pasien yang dikirimkan ke aplikasi android dan web server.

Tahapan dalam kegiatan ini yaitu di hari pertama dilakukan perkenalan dan konsep dari sistem yang akan dilakukan dengan proses sosialisasi ke Tim STIPARK dan perwakilan Instansi.

1. Sosialisasi dan pelatihan Produk ke Mitra STIPARK NTB

Pada tahap ini sesuai gambar 2, tim mahasiswa melakukan sosialisasi terhadap hasil penelitian yang akan di implementasikan dalam kegiatan magang ini melihat dari permasalahan yang sedang terjadi di kalangan masyarakat maupun medis yaitu terkait tentang beberapa kasus pasien isolasi mandiri yang meninggal. Sehingga diperlukan sebuah produk yang nantinya diharapkan bisa bermanfaat buat masyarakat maupun mitra.
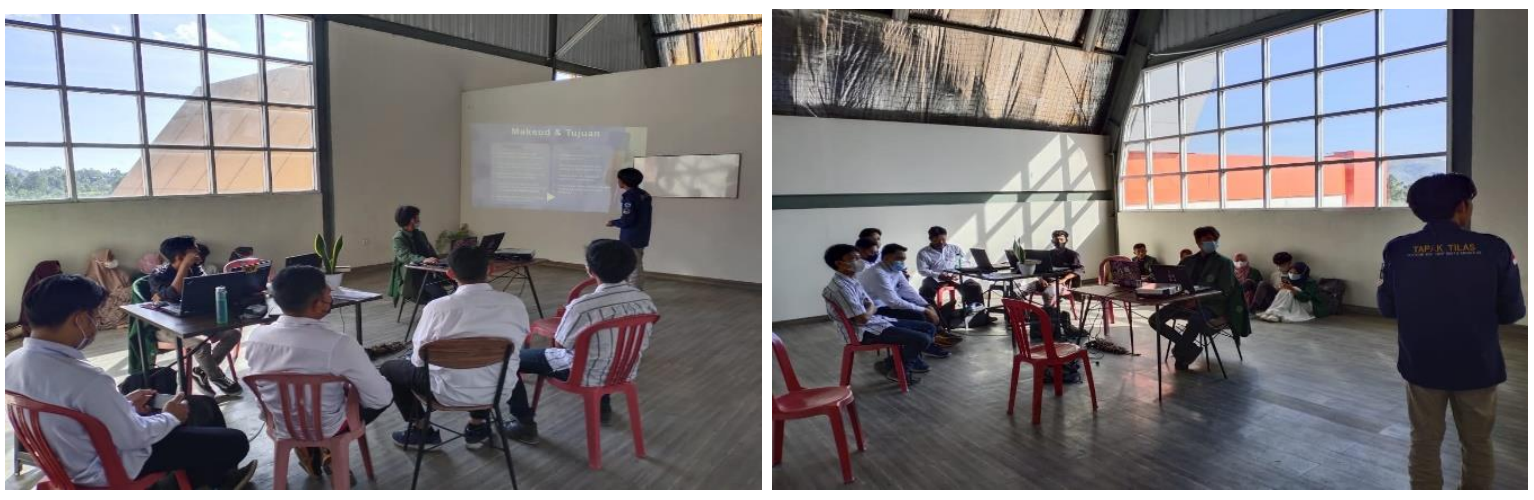

Gambar 2. Sosialisasi Presentasi Produk Inovasi

Hasil dari kegiatan sosialisasi ini pihak STIPARK dan tim mahasiswa sepakat untuk mengimplementasikan hasil penelitian tersebut ke dalam produk sesuai dengan standar industri berupa produk SELMO yaitu sistem monitoring pasien isolasi mandiri ataupun karantina secara realtime berbasis teknologi internet of things (IOT). 


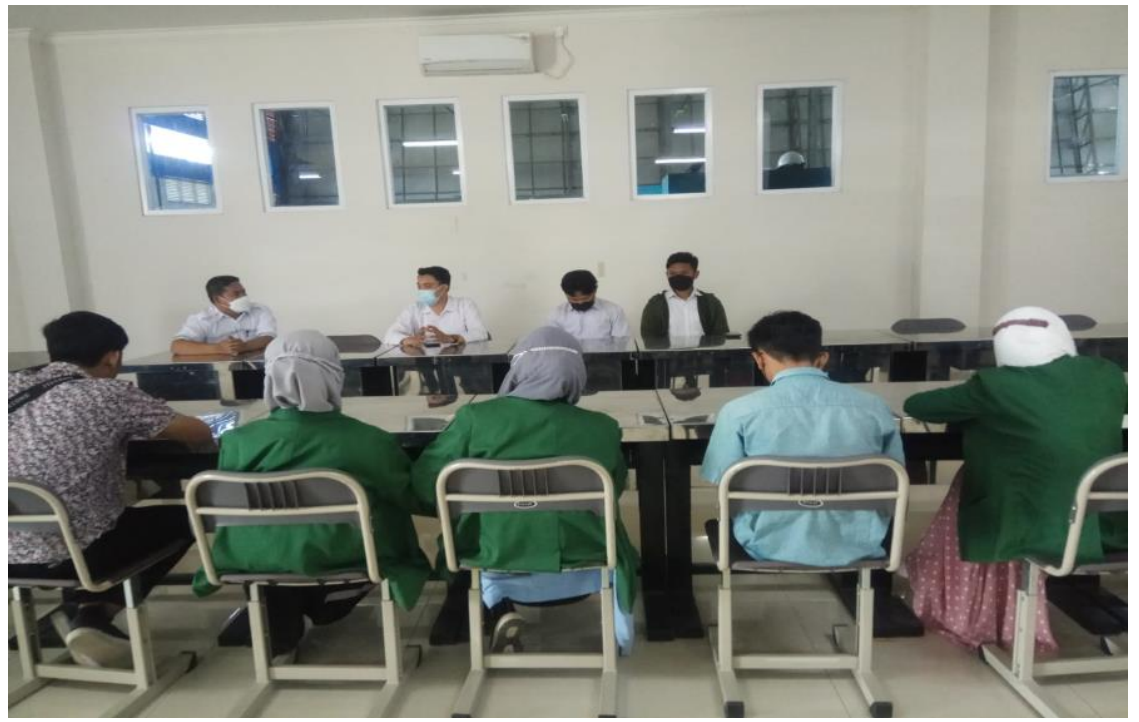

Gambar 3. Rapat koordinasi TIM STIPARK NTB

Pada gambar 3, tim mahasiswa dengan dosen dan tim STIPARK melakukan rapat koordinasi terkait produk inovasi yang akan diimplementasikan pada kegiatan magang industri.

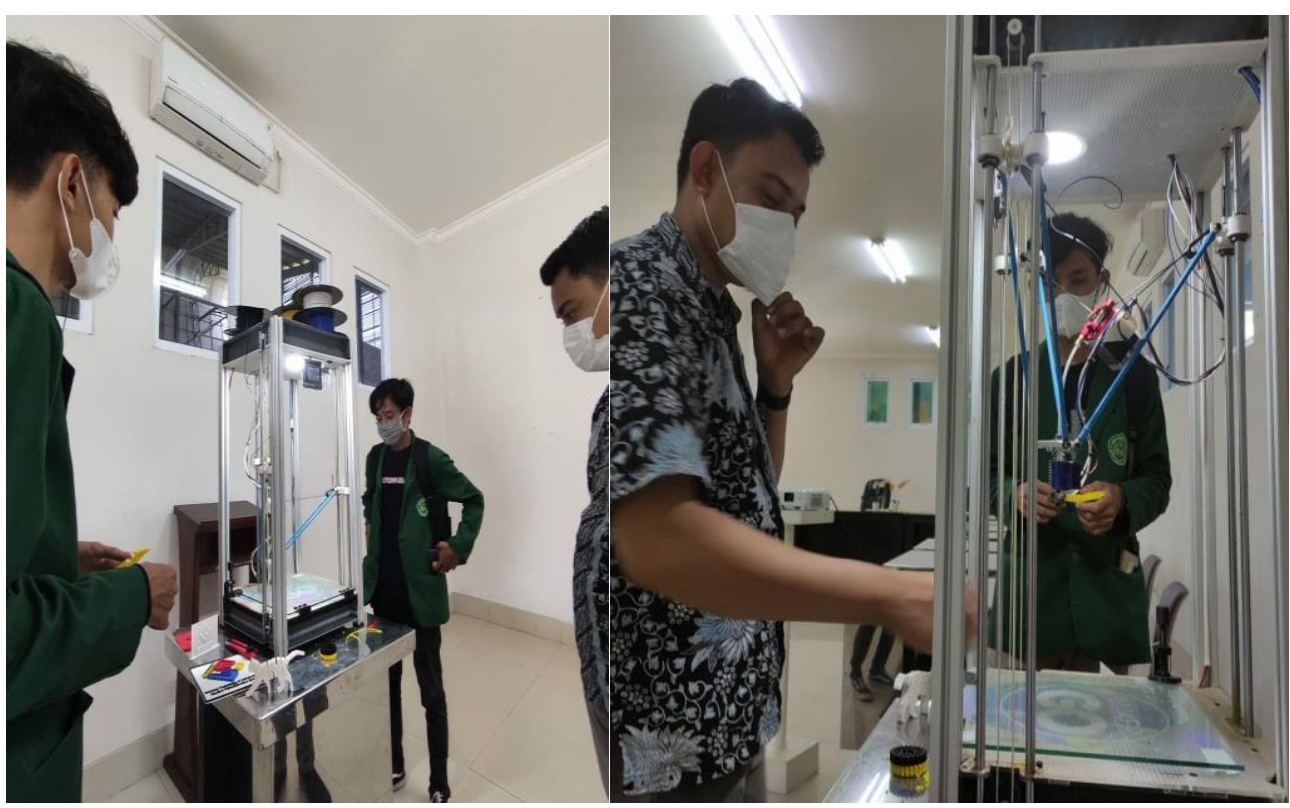

Gambar 4. Pengembangan Produk Inovasi

Pada gambar 4, proses perancangan box untuk pengembangan sebuah produk hasil penelitian agar bentuknya sesuai standar industri.

2. Produk Inovasi Pengembangan untuk Mitra

Pada gambar 5, menunjukkan bentuk produk atau alat untuk membaca data pasien berupa sensor-sensor dan tampilan berupa layar OLED, kemudian pada gambar 6 dan 7 , menunjukkan tampilan dashboard aplikasi monitoring baik berbasis android dan bisa di monitoring berbasis website atau webview. Bentul produk alat inovasi berupa tampilan 
halaman utama yang terdapat informasi mengenai data kondisi pasien baik data suhu ruangan, suhu tubuh, data kadar oksigen (SP02) dan denyut jantung (BPM) (Sofiani dkk., 2021).

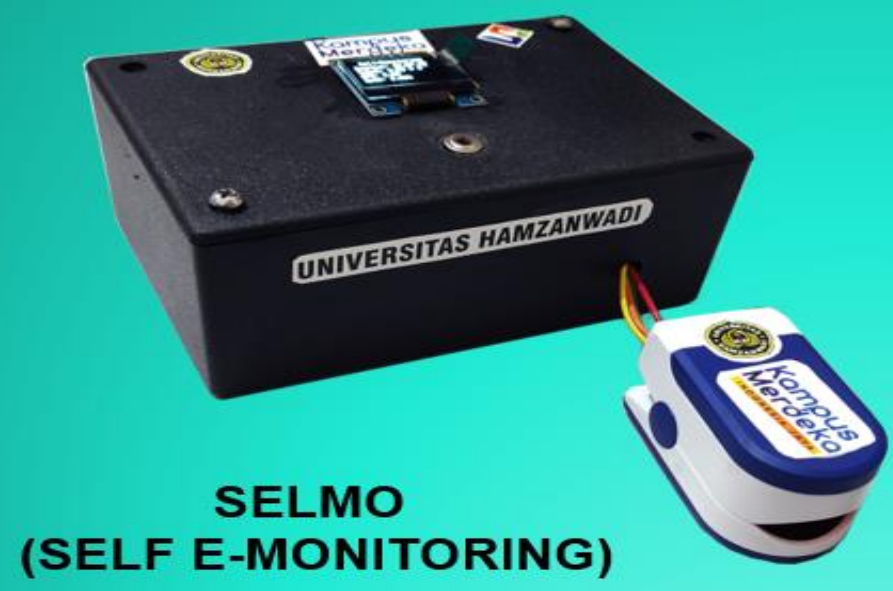

Gambar 5. Tampilan Alat Box SELMO

\section{USER INTERFACE \& Features}

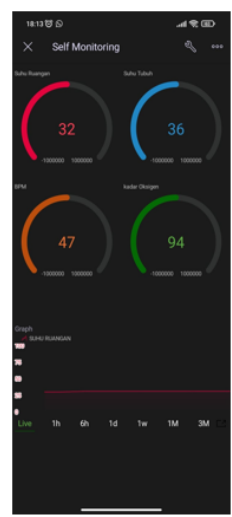

\section{MOBILE APPS}

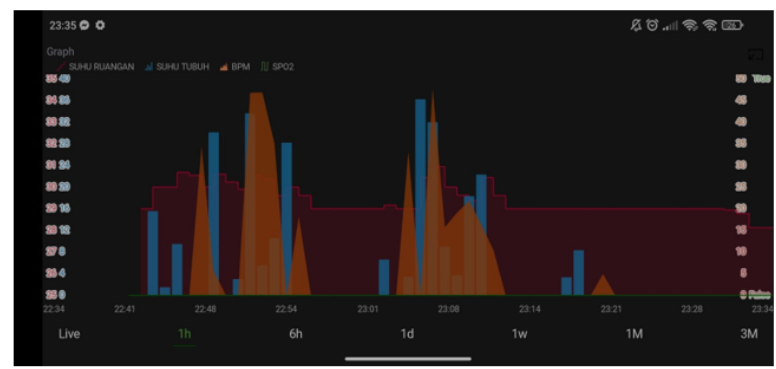

Gambar 6. Tampilan Aplikasi Monitoring Berbasis Android 


\section{USER INTERFACE}

\section{WEB VIEW}

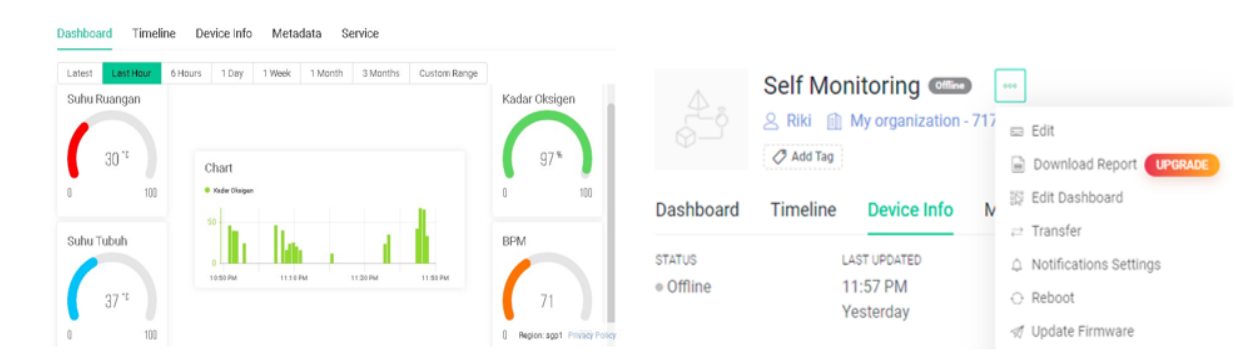

Gambar 7. Tampilan Aplikasi Monitoring Berbasis Web View

\section{PEMBAHASAN}

Kegiatan magang industri yang dilakukan oleh mahasiswa di STIPARK NTB memberikan kontribusi yaitu berupa penerapan produk hasil penelitian dengan melakukan sosialisasi dan pelatihan produk yaitu produk self-monitoring, Dengan adannya alat Self EMonitoring ini dapat diharapkan dapat membantu tim kesehatan dalam penanganan Covid-19 yang masih ada kasus perkembangannya walaupun sedikit dan banyak yang disarankan melakukan isolasi mandiri, adanya beberapa kasus khususnya pada pasien ISOMAN, alat ini dilakukan uji coba dan pengembangan di STIPARK NTB yang nantikan akan bisa di buat dalam bentuk standar industri dan diharapkan akan bermanfaat untuk instansi mitra baik mitra rumah sakit, dinas kesehatan, maupun pelaku usaha homecare. Dari hasil tahap uji coba didapatkan hasil berupa tampilan data kondisi pasien seperti suhu ruangan, suhu tubuh, data kadar oksigen (SP02) dan denyut jantung pasien, penerapan produk didapatkan hasil bahwa alat dapat bekerja dengan baik dengan berhasil mengirimkan data kesehatan pasien dari jarak jauh secara realtime dan dapat dipantau melalui aplikasi di smartphone maupun melalui webiste. Data yang ditampilkan berupa data sensor suhu tubuh, kadar oksigen (SP02) dan denyut jantung (BPM) sehingga dengan adanya alat ini dapat mengefisienkan waktu, dapat dilakukan pemantauan pasien ISOMAN secara rutin dan mengurangi interaksi dengan pasien Covid-19 (Gunawan, dkk., 2021; Nani, dkk., 2021). Hasil dari penerapan produk ini akan dikembangkan dan sudah di referensikan ke dinas terkait seperti dinas kesehatan, mitra rumah sakit melalui program inkubator dari STIPARK NTB. Tahap akhir sekaligus pengenalan produk ke calon mitra dilakukan pada tanggal 17 November 2021 yang di resmikan oleh direktur STIPARK NTB kepada para peserta baik dari kepala dinas provinsi NTB maupun mitra dari tenaga kesehatan. Dan salah satu peserta mitra yang hadir tertarik untuk menerapkan di instansinya. 


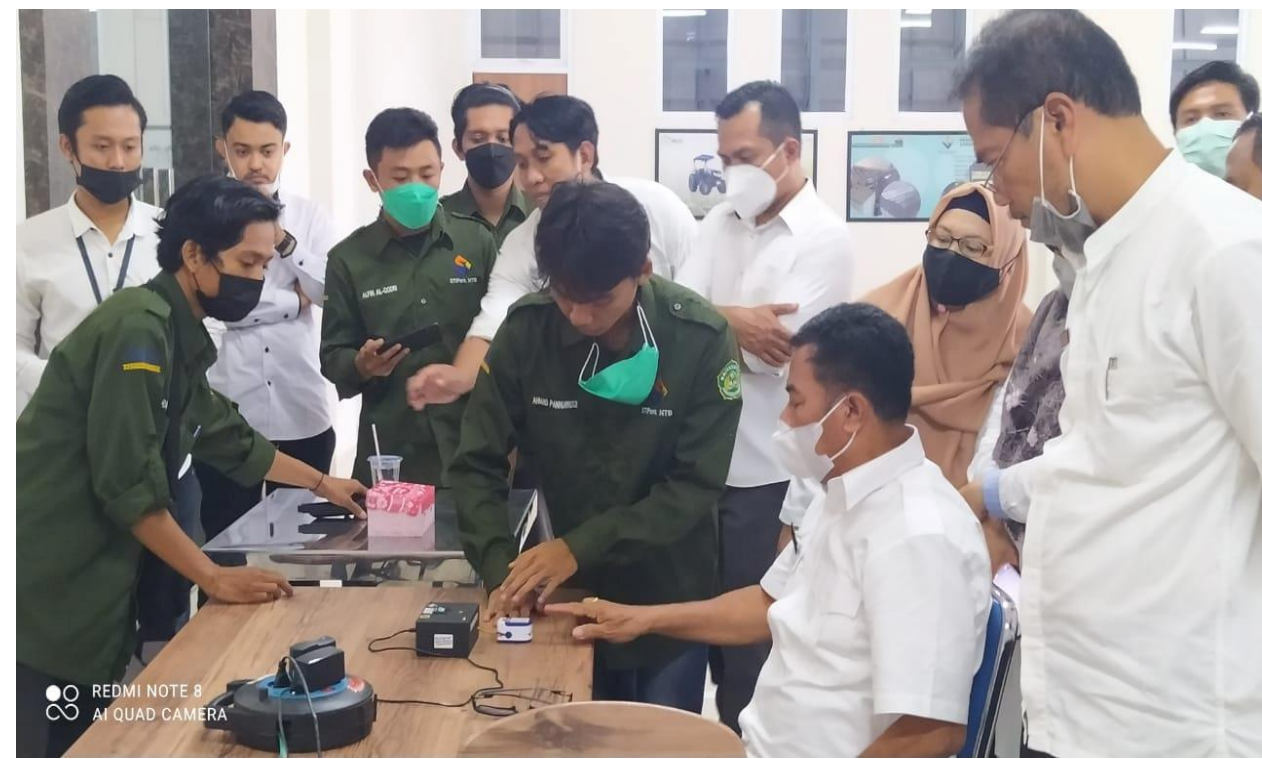

Gambar 8. Tahap uji coba sekaligus pengenalan produk kepada mitra

\section{SIMPULAN}

Smart e- Monitoring adalah sebuah karya inovasi yang merupakan produk hasil penelitian yang di kembangkan dan sosialisasikan ke mitra agar nantinya produk bisa di manfaatkan kepada masyarakat yang membutuhkan baik masyarakat pemerintah maupun mitra pelaku dibidang kesehatan. Produk alat ini berhasil dalam mengirimkan data secara nirkabel atau jarak jauh kemudian menampilkan data kondisi pasien secara realtime yaitu data suhu ruangan, suhu tubuh, data kadar oksigen (SP02) dan denyut Jantung (BPM) pasien, data ini nantinya digunakan oleh petugas medis untuk menganalisis pengambil keputusan tindakan dan membantu memudahkan dalam penanganan pasien ISOMAN tanpa harus sering bersentuhan langsung dengan pasien Covid-19. Walaupun ada kekurangan dalam beberapa kebutuhan data indikator lainnya yang belum lengkap bisa ditampilkan, tapi itu akan menjadi pengembangan selanjutnya.

\section{PERNYATAAN PENULIS}

Bahwa penerapan produk inovasi hasil penelitian ini yang digunakan sebagai bentuk untuk pengabdian masyarakat ini belum pernah di terbitkan pada jurnal pengabdian mana pun.

\section{DAFTAR PUSTAKA}

Arianti, B. D. D., Kholisho, Y. N., Ismatulloh, K., Wirasasmita, R. H., Uska, M. Z., \& Fathoni, A. (2020). Pelatihan Computer Based Test (CBT) Ujian Nasional Untuk Siswa SMK di Lombok Timur. ABSYARA: Jurnal Pengabdian Pada Masyarakat, 1(1), 22-32. https://doi.org/10.29408/ab.v1i1.2408

Gunawan, I., Sudianto, A., \& Sadali, M. (2021). Measuring Body Temperature Based Internet of Things (IoT) Using Esp8266 and Firebase. SISFOTENIKA, 11(1), 91-100.

Pratiwi, C. (2021, June). Prototipe monitoring kesehatan pasien Covid-19 pada masa karantina menggunakan Heartrate dan Oximeter Sensor berbasis Internet of Things (IOT). In Electro National Conference (ENACO) Politeknik Negeri Sriwijaya (Vol. 1, No. 1 Juni, pp. 264-271). 
Putra, Y. K., Sadali, M., Fathurrahman, F., \& Mahpuz, M. (2020). Pelatihan uji kompetensi keahlian siswa sekolah kejuruan menggunakan metode Participatory Learning and Action (PLA). ABSYARA: Jurnal Pengabdian Pada Masyarakat, 1(2), 46-52. https://doi.org/10.29408/ab.v1i2.2772

Nani, N. R. A. N. A., Syafaah, L., \& Nasar, M. (2021). Pengembangan pendeteksi suhu tubuh dan kadar oksigen darah untuk pencegahan dini penularan Covid-19. In Prosiding SENTRA (Seminar Teknologi dan Rekayasa) (No. 6, pp. 105-114).

Saputra, M. R. (2020). Telemonitoring Perburukan Gejala Pada Pdp Covid-19 Karantna Madiri Berbasis Iot. Disertation, Universitas Muhammadiyah Surakarta.

Septiana, Y. T., Pramukantoro, E. S., \& Primananda, R. (2020). Penerapan Antarmuka Transmisi Data EKG Berbasis Komunikasi BLE (Bluetooth Low Energy) Pada Mobile Middleware. Jurnal Pengembangan Teknologi Informasi dan Ilmu Komputer. 4(2), 594-602

Sofiani, I. R., Kharisma, R., \& Syafa'ah, L. (2021). Sistem Monitoring Heart Rate dan Oksigen Dalam Darah Berbasis LoRa. Medika Teknika : Jurnal Teknik Elektromedik Indonesia, 2(2). https://doi.org/10.18196/mt.v2i2.11465

Suhartini, S., Sudianto, A., Gunawan, I., Permana, B. A. C., Ahmadi, H., Fathurrahman, I., Wijaya, L. K., Wasil, M., \& Nurhidayati, N. (2021). Pembinaan kewirausahaan berbasis teknologi untuk mengembangkan jiwa Technopreneurship. ABSYARA: Jurnal Pengabdian Pada Masyarakat, 2(1), 1-7. https://doi.org/10.29408/ab.v2i1.2574

Sutisna, U., Elkarimah, M. F., \& Asma, F. R. (2020). Pengembangan kompetensi profesional guru PAI melalui pemanfaatan teknologi informasi. ABSYARA: Jurnal Pengabdian Pada Masyarakat, 1(2), 9-14. https://doi.org/10.29408/ab.v1i2.2629 